\title{
Crohn's disease: The benefits of minimal surgery
}

\author{
JOE J TJANDRA, MD, VICTOR W FAZIO, MD
}

JJ TJANDRA, VW FAZIO. Crohn's disease: The benefits of minimal surgery. Can J Gastroenterol 1993; 7(2):254-257. The extent of surgery for small bowel Crohn's disease has been controversial. Evidence supporting extensive surgery and minimal surgery (including strictureplasty) is reviewed. Minimal surgery does not appear to be associated with increased morbidity or recurrence rates. The weight of evidence supports the practice of minimal surgery to minimize the risk of iatrogenically-induced short bowel syndrome.

Key Words: Crohn's disease, Strictureplasty

\section{Maladie de Crohn: avantages de la chirurgie minimale}

RÉSUMÉ: L'ampleur de la chirurgie pour la maladie de Crohn du grêle fait l'objet de controverse. Les résultats obtenus par la chirurgie élargie ou minimale (y compris le traitement des rétrécissements de l'intestin) sont passés en revue. La chirurgie minimale ne semble pas associée avec des taux de morbidité ou de récurrence accrus. Le poids de l'évidence appuie la pratique d'une chirurgie minimale pour réduire le risque iatrogène de malabsorption par perte anatomique d'un segment du grêle.
C ROHN'S DISEASE IS POTENTIALLY panintestinal with a high risk of relapse. In our experience, the cumulative recurrence rate after resection of ileocolic disease was $44 \%$ at 10 years and was $33 \%$ after resection of small intestinal disease (1). However, the incidence of recurrence varies between reports (2). Furthermore, microscopic changes of Crohn's disease may be present in a macroscopically normal. appearing bowel (3). As our under- standing of factors in 'surgical recurrence' increases, there has been a change in the philosophy governing surgical treatment towards conservatism to avoid short bowel syndrome. These issues will be specifically discussed.

\section{DEFINITION OF 'RECURRENCE'}

A major reason for a wide variance in the reported 'recurrence' rates fol-
Department of Colorectal Surgery, Cleveland Clinic, Ohio, USA

Correspondence and reprints: Dr Victor Fazio, Chairman, Department of Colorectal Surgery, Cleveland Clinic, 9500 Euclid Avenue, Cleveland, OH 44195, USA lowing resection for Crohn's disease is the difference in the various definitions of 'recurrence'. This can range from a relapse of clinical symptoms with or without endoscopic or radiologic evidence of recurrence to the need for reoperation with or without histologic confirmation. Recurrence rates are highest when the symptomatic criteria alone are used and lowest when the reoperation rate is used. Endoscopic evidence of Crohn's disease may be present without any symptoms. In a study (4), evidence of anastomotic 'recurrence' was recognized endoscopically in as many as $72 \%$ of patients within one year of ileocolic resection and anastomosis. Rigid stenosis was uncommon in the early postoperative period but was present in close to half the patients examined more than three years later (4). Duration of follow-up also varies between reports. Actuarial analysis (5) may be a more accurate method of reporting when length of follow-up varies.

\section{EXTENT OF RESECTION}

In earlier times, radical resection was considered necessary $(6,7)$. The diseased segment with a wide margin of normal bowel on either side and all of the enlarged lymph nodes were removed $(6,7)$. A margin of $10 \mathrm{~cm}$ was considered necessary in some centres 
(8). The literature itself has been confusing with proponents and opponents of radical resection.

All these studies were retrospective (Table 1) and, in some cases, the reliability of analysis of the resection margins was questionable (9). Some studies $(8,10)$ included patients who had residual overt disease in the nonradical group. This would have exaggerated the 'recurrence' rate in the non-radical resection group. In the study by Bergman and Krause (8), recurrences not at the anastomosis were also included in the study; most importantly, the radical operations were performed at a different institution from the nonradical or control operations. Differences in patient population and surgical teams further confuse the outcome. Another study (11) with a short follow-up (Table 1) based the diagnosis of 'recurrence' on radiologic changes alone and clinical symptoms were not considered. It is possible that asymptomatic, radiologic changes of Crohn's disease are more common in the nonradical resection group. Histologic criteria for a positive margin in these studies were not clear.

Several studies, on the contrary, have failed to find any association between the length of resection margin and recurrence (12-14). Furthermore, to preserve small bowel length, the length of the resection margin tends to be inversely related to the length of active Crohn's disease resected, in that patients with long disease segments tend to have short resection margins. As one study showed (14), although a higher recurrence rate was noted with shorter resection margins, it was not independent of the length of active disease resected. Relationship to recurrence was not present when the length of the margin was analyzed independent of the length of active disease in the specimen. Thus, reports claiming a poorer prognosis for short resection margins may reflect a longer length of active disease in these patients.

A more conservative resection may also be applied to patients with diffuse involvement of the small bowel. However, patients with diffuse disease have

TABLE 1

Proponents of radical resection in Crohn's disease

\begin{tabular}{|c|c|c|c|}
\hline \multirow[t]{2}{*}{ Reference } & \multirow{2}{*}{$\begin{array}{c}\text { Follow-up } \\
\text { (years) }\end{array}$} & \multicolumn{2}{|c|}{ Crude recurrence rate (\%) } \\
\hline & & Wide margin & Narrow margin \\
\hline Atwell et al (9) & $<1$ to $>20$ & $32 \%$ & $85 \%$ \\
\hline Bergman and Krause (8) & 10 & $29 \%$ & $84 \%$ \\
\hline Krause et al (10) & 18 & $31 \%$ & $83 \%$ \\
\hline Heed et al (11) & 2 & $28 \%^{*}$ & $52 \%^{*}$ \\
\hline
\end{tabular}

"Cumulative recurrence rate was reported

been shown to have a higher incidence of recurrence than those with singlesite disease (15). This may further account for the higher recurrence rates with a short resection margin in some studies.

\section{MICROSCOPIC DISEASE AT RESECTION MARGINS}

The influence of microscopic disease at resection margins on the recurrence rates has been contentious. Many of the studies on resection margins have been criticized for inclusion of patients with Crohn's colitis (16-20) where the preferred surgical approach may not be segmental resection and the distinction between Crohn's disease and ulcerative colitis can be difficult. In some cases, reoperative cases were included $(16,17)$. Histologic criteria for positive margins were variable $(16,18$ 20) and sometimes not given (21).

Some centres have advocated intraoperative frozen section examinations to ensure disease-free resection margins (16,21-23). However, microscopic changes are easily missed in frozen sections (24). In a study (24), 60 of 61 bowel margins examined by frozen sections were reported as negative but 20 of 61 margins were actually involved by Crohn's disease when examined by permanent histologic sections. Wolff et al (16) reported the importance of microscopic disease at the resection margin on the recurrence rate. Microscopic evidence of disease was defined as mucosal inflammation or ulceration, specifically excluding nonspecific submucosal or intramuscular inflammation. The cumulative recurrence rate for this group $(n=39)$ was $90 \%$ at eight years, compared with $47 \%$ for other patients $(n=658$ ) undergoing resection for Crohn's disease.
However, patients with microscopic disease $(n=39)$ were retrospectively identified from the original pathology report and the histological sections of all operated cases $(n=710)$ were not reviewed with regard to the presence of disease at the resection margins. Furthermore, half of the patients with positive margins had skip areas of active macroscopic disease in the remaining bowel, which is known to be associated with a high recurrence rate $(15,25)$. Thus the two groups of patients were not comparable.

Within the past decade, many studies have shown that microscopic abnormalities at resection margins have little influence on anastomotic recurrence $(13,17,18,20,21,26)$. However, in some of these studies $(18,26)$, minor histologic changes were included as evidence of a positive margin.

To clarify some of these issues, a study of 100 patients having their first resection for small bowel or small and large bowel Crohn's disease was undertaken at the Cleveland Clinic (27). Diagnosis of recurrence was defined as the presence of symptoms with a demonstrable lesion at or near the anastomosis. Resection margins were categorized by a single gastrointestinal pathologist as being histologically normal, showing changes of a nonspecific nature, showing changes suggestive of Crohn's disease and showing changes diagnostic of Crohn's disease. The histologic features evaluated for each resection margin are shown in Table 2.

Recurrence at the anastomosis occurred in $50 \%$ of the patients at a mean follow-up of 11.5 years. The cumulative recurrence rates for the four margin categories were not statistically different. Recurrence was also not associated with any specific clinical or 


\begin{tabular}{l} 
TABLE 2 \\
Histological features evaluated for \\
each resection margin \\
\hline Mucosal/submucosal edema \\
Inflammation \\
- neutrophils in mucosa/submucosa \\
- chronic inflammatory cells in \\
mucosa \\
Lymphoid aggregates \\
Pyloric metaplasia \\
Fibrosis of muscularis mucosae/sub- \\
mucosae \\
Cryptitis/crypt abscesses \\
Mucosal erosions and ulcers \\
Fissural ulcers \\
Granuloma \\
Villous shortening \\
Mucin depletion \\
Neuronal hyperplasia \\
Transmural inflammation
\end{tabular}

Adapted from Kotanagi et al (27)

histologic feature. Furthermore, the cumulative recurrence rate of those patients in the study who fulfilled the criteria of Wolff et al (16) of a positive margin was not significantly different from the recurrence rates of any of the four categories (27).

Whether or not frozen-section examination of resection margins in Crohn's disease affects the rate of anastomotic recurrence is not completely clear because a controlled prospective trial has not yet been done. All studies have been retrospective. However, the body of evidence to date supports a conservative attitude in intestinal resection, removing only overtly involved intestine. The safety and efficacy of such an approach is further endorsed by the following discussion on strictureplasty.

\section{STRICTUREPLASTY}

As an alternative to extensive repeat resections, Lee from Oxford (28) pioneered the technique of strictureplasty to relieve obstruction from short fibrotic strictures of the small bowel. In subsequent studies (Table 3), it has been shown to be safe, effective and has the added advantage of bowel preservation. The principle and nomenclature of strictureplasty is similar to pyloroplasty. The surgical techniques have been described in detail elsewhere $(34,35)$.

TABLE 3

Major studies on strictureplasty for Crohn's disease

\begin{tabular}{lccc}
\hline Centre & Reference & $\begin{array}{c}\text { Patient } \\
(\mathrm{n})\end{array}$ & $\begin{array}{c}\text { Strictureplasties } \\
(\mathrm{n})\end{array}$ \\
\hline 1982 Oxford & 28 & 9 & 9 \\
1987 Birmingham & 29 & 52 & 148 \\
1989 Oxford & 30 & $24^{*}$ & 99 \\
1989 Toronto & 31 & 14 & 37 \\
1990 Boston & 32 & 13 & 55 \\
1992 Cleveland & 33 & 116 & 452 \\
\hline
\end{tabular}

*includes Dr Lee's original patients (28)

A total of 452 strictureplasties have been performed in 116 patients at the Cleveland Clinic (33). The median number of strictureplasties per patient was three (range, one to 15). Short strictures up to $10 \mathrm{~cm}$ are reconstructed transversely by Heinecke-Mikulicz and longer strictures up to $30 \mathrm{~cm}$ by Finney strictureplasty as in a side-to-side anastomosis. Synchronous resections were undertaken in $71(61 \%)$ patients. In general, resections were performed for acute inflammatory phlegmon, overt perforation, fistulae, strictures longer than $30 \mathrm{~cm}$ and for multiple strictures within a short segment.

There was no operative mortality. The median duration between operation and discharge was nine days (range, six to 27 days). Major complications were uncommon despite the inclusion of actively inflamed bowel in the suture line. Enterocutaneous fistulae with or without associated intraabdominal abscess developed in five $(4 \%)$ patients. In two $(2 \%)$ additional patients, intra-abdominal abscess occurred without demonstrable fistula on contrast examination of the intestines. Reoperation for these septic complications was needed in two patients. The remainder were successfully managed with parenteral nutrition, antibiotics, somatostatin for fistula and computer tomographic-guided drainage for intraabdominal abscess.

The median follow-up was three years (range six months to seven years). Relief of obstructive symptoms, as assessed subjectively by the patient, was achieved in 115 (99\%) patients. Steroid use was $67 \%$ before and $23 \%$ at six months after surgery. Symptomatic recurrence developed in 28 (24\%) patients. Evidence of disease was demonstrated on contrast examination of the small bowel. Of this group, symptomatic restricture occurred in 10 $(2.8 \%)$ previous strictureplasty sites. New strictures $(n=52)$ and perforative disease $(n=5)$ unrelated to previous strictureplasty sites developed in 23 (20\%) patients and five $(4 \%)$ patients respectively. Seventeen patients had further surgery for recurrent symptoms. Thus, even though anastomosis is performed through diseased bowel, recurrence tends to develop at other sites.

In the absence of frank sepsis, strictureplasty can also be performed in patients with active (36) and diffuse (37) small bowel Crohn's disease. Multiple (four or more) strictureplasties have been performed in patients with diffuse Crohn's disease of the small bowel (37). In this group of patients with a median number of seven strictureplasties, the complication rate and outcome is no worse than for those who had undergone isolated strictureplasties $(28-33,37)$. In another study (38), actuarial analysis has shown no difference in site-specific recurrence (based on the need for reoperation at that site) between patients undergoing conventional resection and those undergoing strictureplasty.

\section{CONCLUSIONS}

It appears from these studies that diseased resection margins are of little significance with regard to recurrence rate. Conservative resection, removing only overt diseased segment, is therefore recommended. In selected cases of Crohn's disease with stricture, strictureplasty can accomplish symptomatic relief safely, minimize the risk of short bowel syndrome and is a useful adjunct to resection. 


\section{REFERENCES}

1. Lock MR, Farmer RG, Fazio VW, Jagelman DG, Lavery IC, Weakley FL. Recurrence and reoperation for Crohn's disease: The role of disease location in prognosis. N Engl J Med 1981;304:1586-8.

2. Williams JG, Wong WD, Rothenberger DA, Goldberg SM. Recurrence of Crohn's disease after resection. Br J Surg 1991;78:10-9.

3. Dunne WT, Cooke WT, Allan RN. Enzymatic and morphometric evidence for Crohn's disease as a diffuse lesion of the gastrointestinal tract. Gut 1977;18:290-4.

4. Rutgeerts P, Geboes K, Vantrappen G, Kerremans R, Coenegrachts JL, Coremans G. Natural history of recurrent Crohn's disease at the ileocolonic anastomosis after curative surgery. Gut 1984;25:665-72.

5. Anderson RP, Bonchek LI, Grunkemeier GL, Lambert LE, Starr A. The analysis and presentation of surgical results by actuarial methods. J Surg Res 1974;16:224-30.

6. Garlock JH, Crohn BB. An appraisal of the results of surgery in the treatment of regional ileitis. JAMA 1945;127:205-8.

7. De Dombal FT, Burton IL, Goligher JC. Recurrence of Crohn's disease after primary excisional surgery. Gut 1971;12:519-27.

8. Bergman L, Krause U. Crohn's disease: A long-term study of the clinical course in 186 patients. Scand J Gastroenterol 1977;12:937-44.

9. Atwell JD, Duthie HL, Goligher JC. The outcome of Crohn's disease. $\mathrm{Br}$ ] Surg 1965;52:966-72.

10. Krause U, Ejerblad S, Bergman L. Crohn's disease: A long-term study of the clinical course in 186 patients. Scand J Gastroenterol 1985;20:516-24.

11. Heen LO, Nygaard K, Bergan A. Crohn's disease: Results of excisional surgery in 133 patients. Scand J Gastroenterol 1984;19:747-54.

12. Trynka YM, Glotzer DJ, Kasdon E], Goldman H, Stear ML, Goldman LD. Long-term outcome of restorative operation in Crohn's disease. Ann Surg 1982;196:345-55.

13. Speranza V, Simi M, Leardi S, Del Papa M. Recurrence of Crohn's disease: are there any risk factors? ] Clin Gastroenterol 1986;8:640-6.

14. Hamilton SR, Boitnott JK, Morson BC. Relationships of disease extent and margin lengths to recurrence of Crohn's disease after ileocolonic anastomosis. Gastroenterology 1981;80:1166.

15. Michelassi F, Balestracci T, Chappele R, Block G. Primary and recurrent Crohn's disease. Experience with 1379 patients. Ann Surg 1991;214:230-40.

16. Wolff BG, Beart RW Jr, Frydenberg HB, Weiland LH, Agrez MV, Ilstrup DM. The importance of disease-free margins in resection for Crohn's disease. Dis Colon Rectum 1983;26:239-43.

17. Pennington L, Hamilton SR, Bayless TM, Cameron JL. Surgical management of Crohn's disease: influence of disease at margin of resection. Ann Surg 1980;192:311-7.

18. Heuman R, Boeryd B, Bolin T, Sjodahl $R$. The influence of disease at the margin of resection on the outcome of Crohn's disease. Br J Surg 1983;70:519-21.

19. Chardavoyne R, Flint GW, Pollack S, Wise L. Factors affecting recurrence following resection for Crohn's disease. Dis Colon Rectum 1986;29:495-502.

20. Adloff M, Arnaud JP, Ollier JC. Does the histologic appearance at the margin of resection affect the postoperative recurrence rate in Crohn's disease? Am Surg 1987;53:543-6.

21. Karesen R, Serch-Hanssen A, Thoresen BO, Hertzberg J. Crohn's disease: Long-term results of surgical treatment. Scand J Gastroenterol 1981;16:57-64.

22. Edwards H. Crohn's disease: An inquiry into its nature and consequences. Ann R Coll Surg Engl 1969;44:121-39.

23. Colcock BP. Operative technique in surgery for Crohn's disease and its relationship to recurrence. Surg Clin North Am 1973;53:375-80.

24. Hamilton SR, Reese J, Pennington L, Boitnott JK, Bayless TM, Cameron JL. The role of resection margin frozen section in the surgical management of Crohn's disease. Surg Gynecol Obstet 1985; 160:57-62.

25. Smith RC, Rhodes J, Heatley RV, et al. Low dose steroids and clinical relapse in Crohn's disease: a controlled trial. Gut 1978;19:606-10.

26. Cooper JC, Williams NS. The influence of microscopic disease at the margin of resection on recurrence rates in Crohn's disease. Ann R Coll Surg Engl 1986;68:23-6.

27. Kotanagi H, Kramer K, Fazio V, Petras R. Do microscopic abnormalities at resection margins correlate with increased anastomotic recurrence in Crohn's disease? Dis Colon Rectum 1991;34:909-16.

28. Lee ECG, Papaioannou N. Minimal surgery for chronic obstruction in patients with extensive or universal Crohn's disease. Ann R Coll Surg Engl 1982;64:229-33.

29. Alexander-Williams J, Haynes IG. Up-to-date management of small bowel Crohn's disease. Adv Surg 1987;20:245-64.

30. Dehn TCB, Kettlewell MGW, Mortensen N, Lee ECG, Jewell DP. Ten-year experience of strictureplasty for obstructive Crohn's disease. $\mathrm{Br}$ J Surg 1989;76:339-41.

31. Silverman RE, McLeod RS, Cohen Z. Strictureplasty in Crohn's disease. Can J Surg 1989;32:19-22.

32. Pritchard TJ, Schoetz DJ, Caushaj FP, et al. Strictureplasty of the small bowel in patients with Crohn's disease. Arch Surg 1990;125:715-7.

33. Tjandra JJ, Fazio VW, Lavery IC, Church JM, Milsom JW, Oakley JR. Long-term follow up of strictureplasty in Crohn's disease. Dis Colon Rectum. (In press)

34. Tjandra JJ, Fazio VW. Strictureplasty in Crohn's disease. In: Cameron JL, ed. Current Surgical Therapy, 4th edn. Philadelphia: BC Decker, 1992;108-13.

35. Fazio VW. Conservative surgery for Crohn's disease of the small bowel. The role of strictureplasty. Med Clin North Am 1990;74:169-81.

36. Fazio VW, Galandiuk S, Jagelman DG, Lavery IC. Strictureplasty in Crohn's disease. Ann Surg 1989;210:621-5.

37. Tjandra JJ, Fazio VW, Lavery IC. Results of multiple ( $\geq 4)$ strictureplasties in Crohn's disease. Aust NZ J Surg. (In press)

38. Sayfan Wilson DAL, Allan A, Andrews $\mathrm{H}$, Alexander-Williams J. Recurrence after strictureplasty or resection for Crohn's disease. Br J Surg $1989 ; 76: 335-8$. 


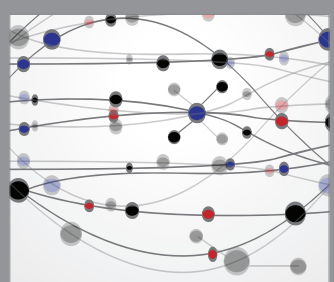

The Scientific World Journal
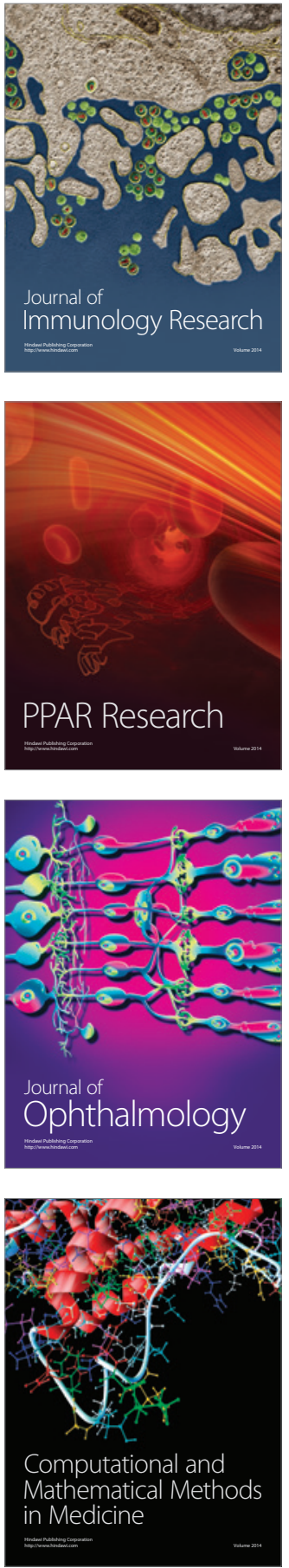

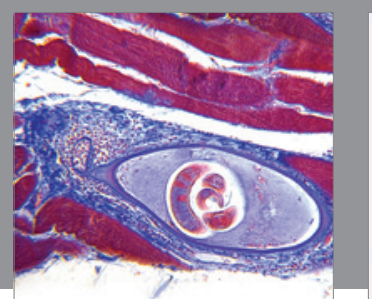

Gastroenterology Research and Practice

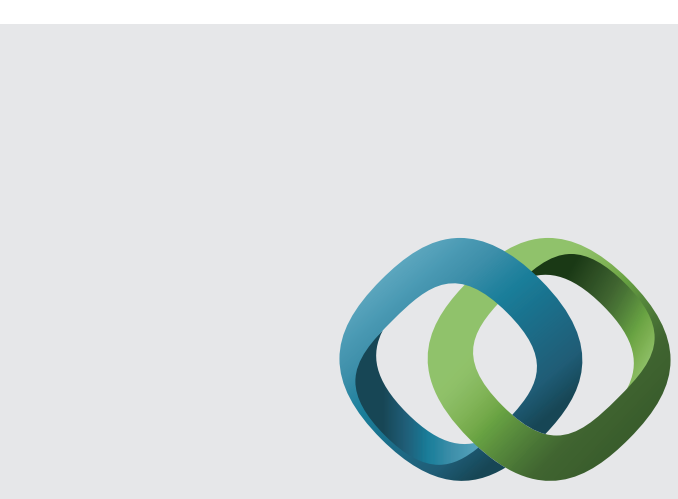

\section{Hindawi}

Submit your manuscripts at

http://www.hindawi.com
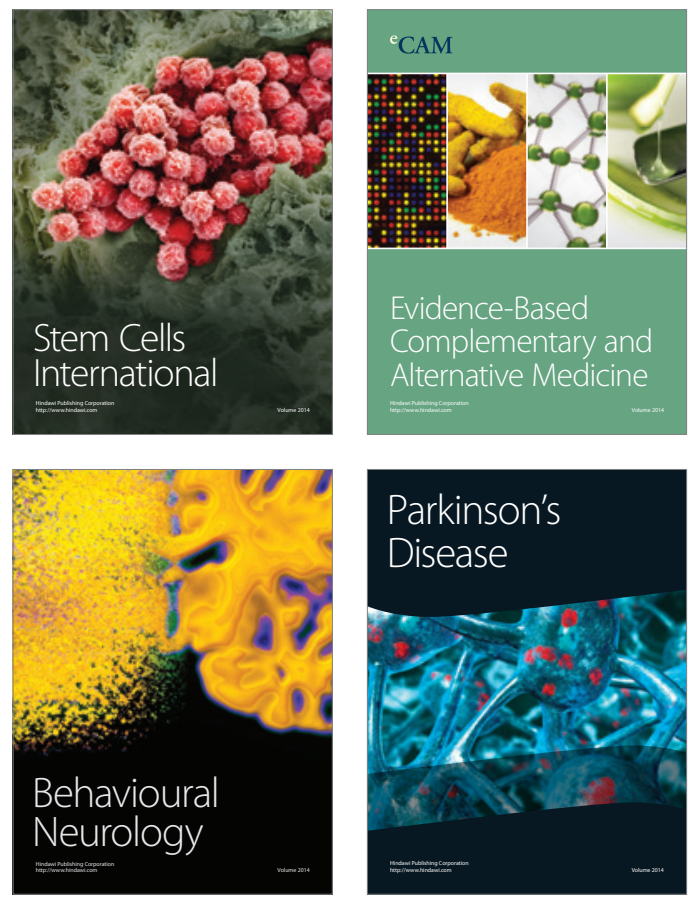
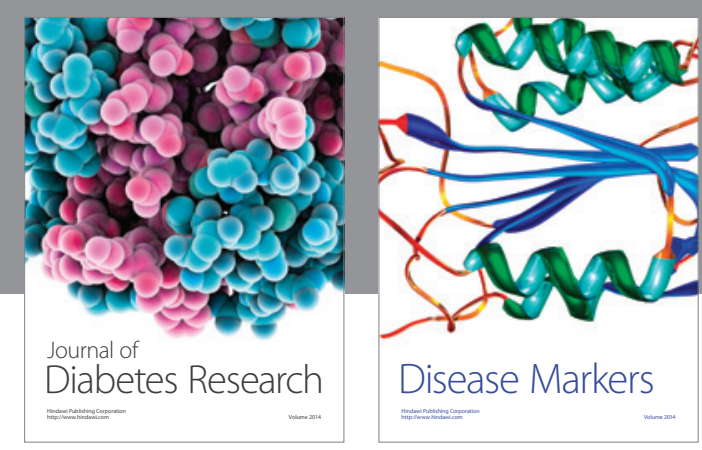

Disease Markers
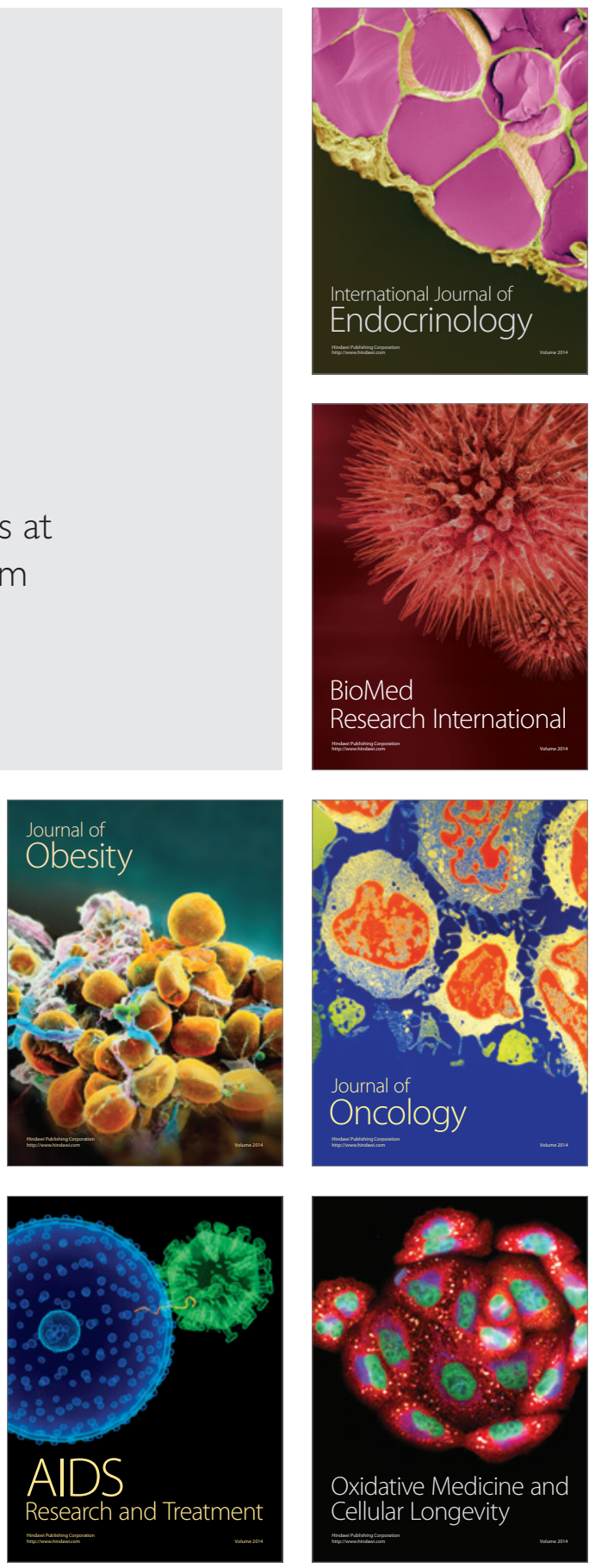